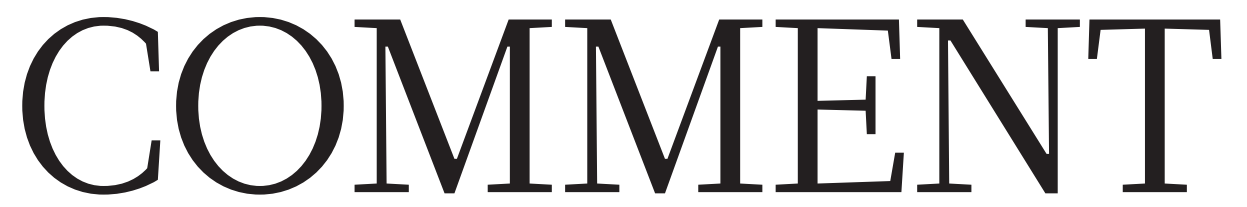

MATERIALS An entertaining journey through the weird world of liquids p.30
StRuctural biology Nobel memoir relives the ribosome marathon $\mathbf{p . 3 2}$
PoLIcY Power and bias shape science too - be frank about it in syntheses p.33
GENE EDITING Europe's politicians must put their trust in plant science $\mathbf{p . 3 3}$

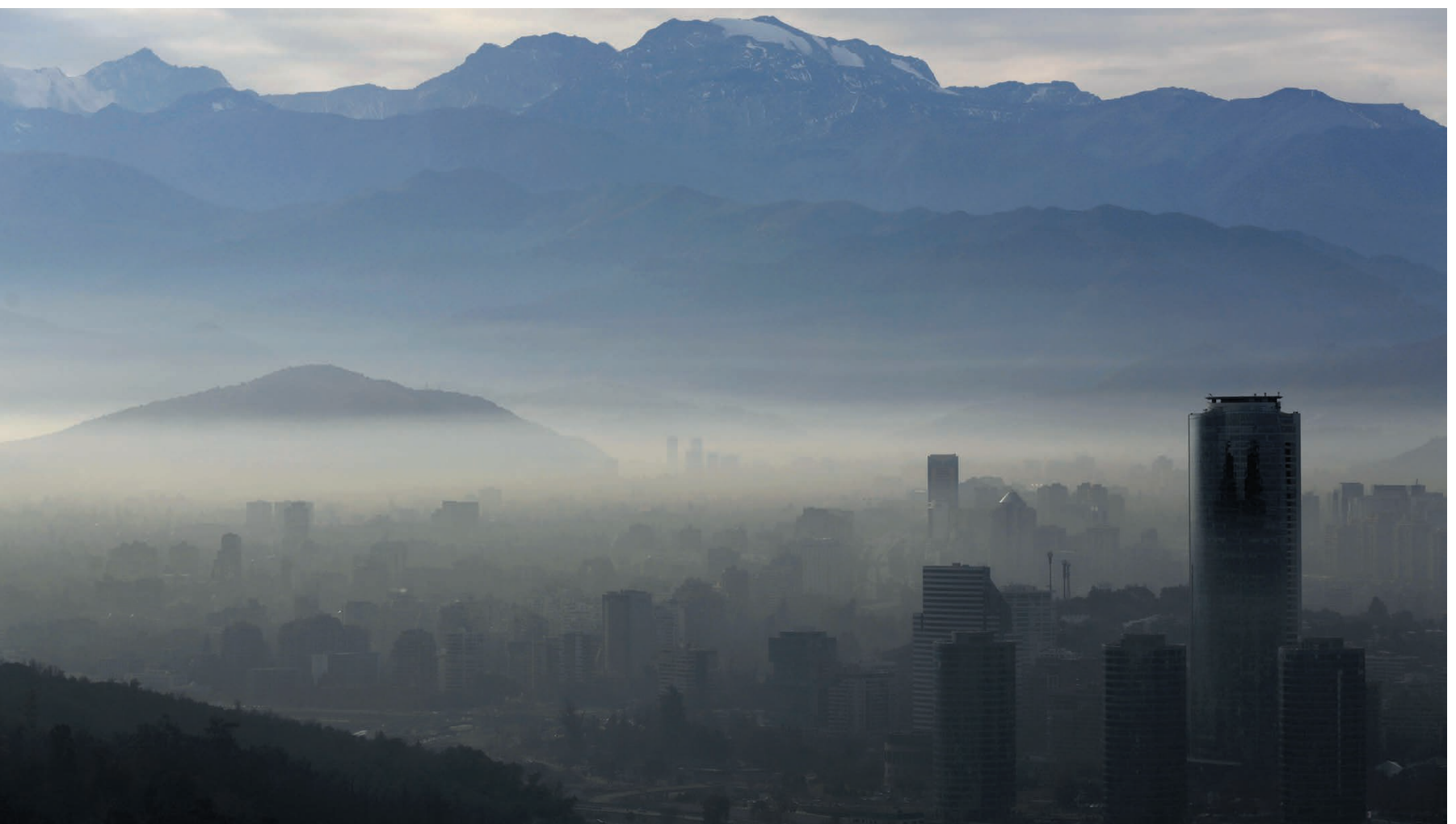

Smog envelopes Santiago in Chile.

\title{
Five steps to improve air-quality forecasts
}

A worldwide monitoring and modelling network would reduce the dramatic toll of air pollution on health and food production, urge Rajesh Kumar and colleagues.

even million people die every year from $\mathrm{S}$ the effects of air pollution. More than $90 \%$ of such deaths are in developing countries ${ }^{1}$. Across southern Asia, levels of fine particulate matter $\left(\mathrm{PM}_{2.5}\right)$ and surface ozone exceed the World Health Organization (WHO) limits for much of the year ${ }^{2}$. Ozone damage to crops and plants - especially to soya beans, wheat and maize (corn) - results in 79 million to 121 million tonnes of lost produce globally, at a cost of US $\$ 11$ billion to $\$ 18$ billion $^{3}$. India's crop losses alone would feed 94 million people ${ }^{4}$. All this costs the world's economy US $\$ 5$ trillion per year ${ }^{5}$.

But air pollution often goes unmonitored.

Some of the fastest-growing cities in Africa, including Lagos, Kinshasa, Abidjan and Dakar, have no air-quality alert systems. Governments can be reluctant to acknowledge the problem, or lack the tools to address it. There is no international strategy for dealing with the issue. And few people are trained in how to collect and interpret air-quality data.

Improvements can take decades. It took the US city of Atlanta, Georgia, 15 years to reduce emissions from power plants by around $80 \%$ and from traffic by up to $90 \%$, avoiding more than 50,000 hospital visits for asthma and lung diseases (ref. 6). Los Angeles in California took 50 years to reduce ozone levels by two-thirds ${ }^{7}$.

Forecasts of hazardous air pollution are crucial to help reduce exposure. Vulnerable people can avoid strenuous outdoor activities or stay indoors. Schools might restrict outdoor sports activities, parents can limit the time their children spend outdoors and doctors might advise their patients to stay inside when levels are high. In Canada, 
> for example, daily forecasts have helped to decrease the number of asthma-related emergency-department visits by $25 \%$ (ref. 8 ).

City managers can also take steps to limit pollution. For example, Santiago in Chile restricts driving and certain industries during predicted periods of high pollution. These measures have reduced the $\mathrm{PM}_{2.5}$ concentrations by $20 \%$ and avoided around 8 deaths each day ${ }^{9}$. However, efforts to ban cars on polluted days in Delhi have had little effect ${ }^{10}$.

Many parts of North America and Europe provide daily broadcasts of airquality forecasts. But across much of Asia, Africa and South America, smog still arrives unannounced. Predictions require advanced computer models and regional weather forecasts; both are lacking across the developing world.

Access to such systems needs to be made global. Local air quality is affected by the intercontinental transport of air pollutants and distant weather events such as the El Niño Southern Oscillation (ENSO). Denser sampling of pollution data would tell air-quality managers which activities are most dangerous and where the worst pollution is coming from - road traffic or industry, say.

Most forecasts of air quality cover two to five days. Extending this to seven to ten days - similar to alert periods for hurricanes and floods - would give communities and hospitals more time to prepare. Seasonal forecasts would give farmers the chance to shift their planting and harvesting dates and choose resistant crops. Such extensions, as well as predictions that span seasons, will be helped by the ongoing efforts to improve weather forecasts and predict emissions from wildfires.

Rolling out a global forecasting system for air quality will take five advances: expanding observing networks; improving models; devising metrics and tools for quantifying air pollution; disseminating the information; and training experts. These steps align with the priorities for weather and climate set out by the World Meteorological Organization (WMO) ${ }^{11}$.

We call on the WMO, the WHO, the United Nations Environment Programme (UNEP) and the Food and Agriculture Organization of the UN (FAO) to lead the development of an international programme for air-quality monitoring and prediction. Financial institutions such as the World Bank and non-governmental organizations should support air-quality initiatives.

\section{FIVE STEPS}

Monitoring. Levels of ozone, $\mathrm{PM}_{2.5}$, carbon monoxide, nitrogen oxides, sulfur dioxide, aerosols and other pollutants need to be tracked globally, at least daily and ideally hourly. Satellite, aircraft, balloon and ground-based instruments will all be needed. Upcoming geostationary missions such as the US Tropospheric Emissions: Monitoring of Pollutants; the Korean Aerospace Research Institute (KARI) Geostationary Environmental Monitoring Spectrometer; and the European Copernicus Programme's Sentinel-4 instruments will soon be able to track pollutants continuously over North America, Asia and Europe. Governments should launch more such satellites or drones to cover other continents. The costs (of $\$ 50$ million to $\$ 100$ million) are small relative to the economic losses from air pollution.

On the ground, air-quality monitoring networks need to be established in Africa, South America and southeast Asia. With about 1 station per urban neighbourhood and around 100 sta-

tions providing a

baseline outside

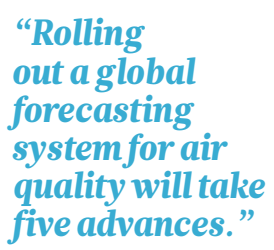

cities, these could complement the system for air hundreds of Global quality will talke Earth Observatory five advances." stations that have been proposed for tracking many environmental compounds ${ }^{12}$. Local scientists will need to be trained to gather the data, with support from governments and multilateral exchange programmes for researchers.

All countries should share their air-quality information. Some do already; many do not. There is no international authority that organizes this. The WMO facilitates such sharing for weather data, and it should coordinate an international agreement and devise quality controls and operating guidelines for air quality, too. Metadata should be included (such as the height of a detector above ground, or its distance from the nearest building, tree, road or industrial stack) as well as measurement errors.

Modelling. Researchers must improve regional and urban air-quality prediction models. These combine weather and atmospheric composition, emissions records and ground and space observations. The models should pinpoint major sources of pollution in cities, such as buildings or roads. And they should track daily cycles, for example in pollution from traffic, as well as decadal changes in weather patterns and emissions. Natural emissions, including those from wildfires, must be accounted for.

Uncertainties must be quantified to avoid false alarms or missed episodes. Inventories that collate emissions from various sources (such as residential and industrial buildings, power, traffic, agriculture and forest fires) are a major source of error, especially in developing countries where reporting is sparse. Such data are often years out of date. Biased measurements and poorly understood physical and chemical processes (such as organic chemistry in the atmosphere, aerosol microphysics and deposition mechanisms) also introduce uncertainties.

Many developing countries do not have the computing power to model air quality. This capability should be added to existing weather-forecasting systems. Large institutions with advanced supercomputers should run the global forecasts, such as the European Centre for Medium-Range Weather Forecasts (ECMWF) and the US National Center for Atmospheric Research (NCAR). National meteorological, air-quality and environmental services must tailor models to local needs. Cloud computing can broaden access, and the ECMWF is trialling this for its weather forecasts.

Interpretation. Researchers need to understand the processes that control air pollution in particular places and over the longer term. They should develop tools to help policymakers and city managers evaluate

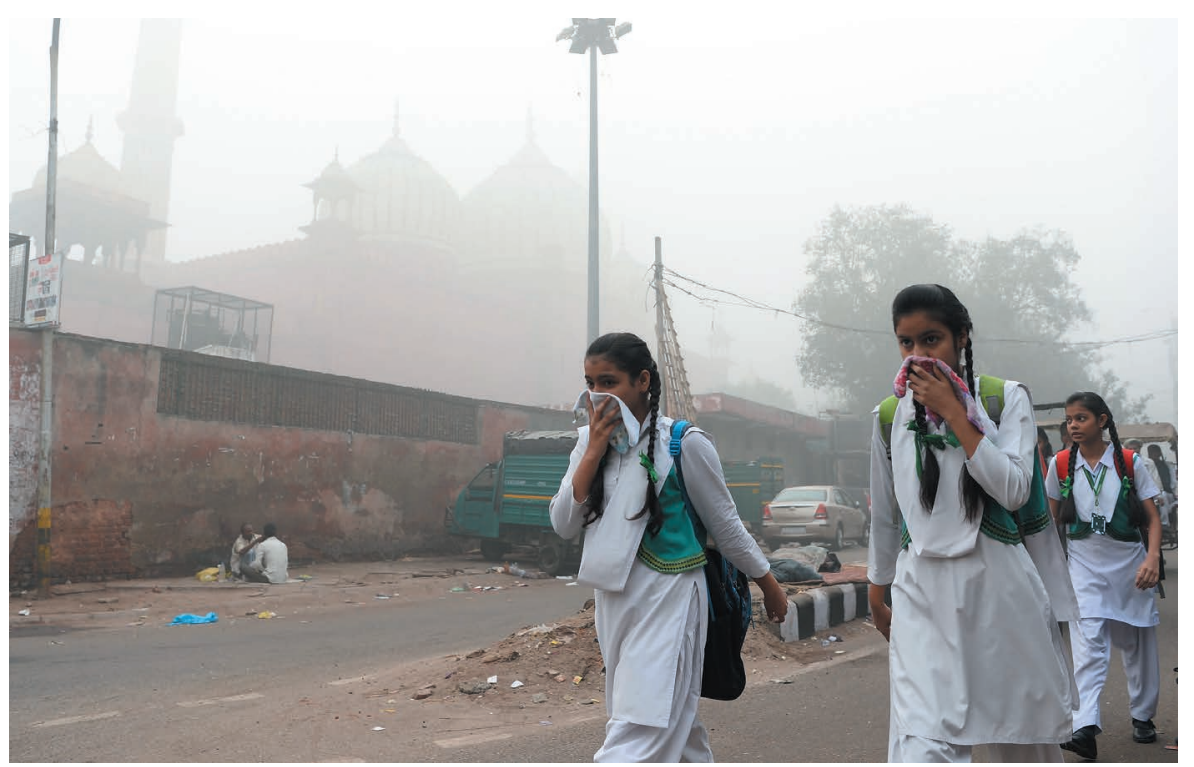

Schoolchildren walk through smog in New Delhi. 


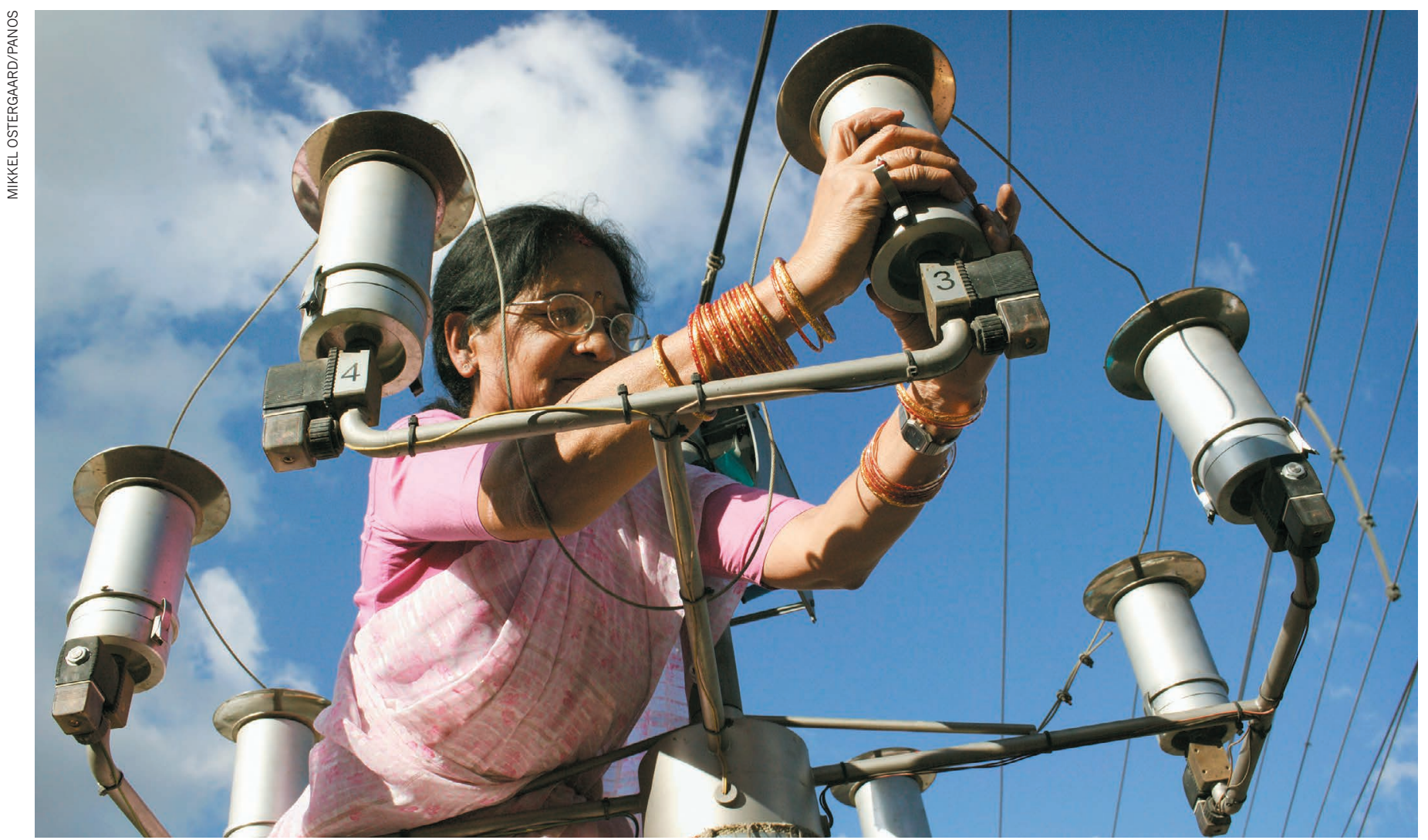

An air-pollution monitoring device in Nepal.

the impacts of regulations, economic policies and urbanization on air quality.

Broad collaborations will be needed. For example, the Partnership with China on Space Data (PANDA) project is bringing together air-quality scientists and officials from Europe and China to develop warning systems for 28 Chinese cities. Similar partnerships are springing up in South America and India, but still need to be developed for Africa and southeast Asia.

Dissemination. National meteorological, air-quality and environmental service providers should calculate health and air-quality indices based on pollutant concentrations, similar to those used in North America and Europe. For instance, the Air Quality Index published by the US Environmental Protection Agency reports how polluted the air is (on a scale of 0-500) and the health effects (such as unhealthy for sensitive groups, or hazardous for everyone). These indices should be explained and released to the public and to hospitals through websites, mobile messaging and so on. London, UK, and Riga, Latvia, issue text alerts on air quality, for example. Air quality could be added to other alert apps, such as one indicating risks from lightning strikes in Andhra Pradesh, India. Technology companies are showing more interest in air-quality monitoring and forecasting. Google, for instance, has been mapping air quality since 2014 with its street-view cars, and IBM has launched a global initiative called Green Horizons, in which air-quality forecasting is a key component.

Training and education. Students, environmental engineers and early-career scientists in developing countries need training in how to measure air quality and climate change and interpret the results. Exchanges of scientists between developed and developing countries could be arranged through programmes such as the European Commission’s Marie Skłodowska-Curie Actions. Massive open online courses are a great opportunity to gain detailed first hand insight. In October, for instance, the European Organisation for the Exploitation of Meteorological Satellites and the ECMWF are running a course on the free platform Iversity, called Monitoring Air Quality from Space, which will explain more about the data being gathered and delivered in the Copernicus Programme. The public and authorities need to understand how to change behaviours, for example by avoiding driving when pollution is bad. Incentives will be needed, such as subsidies for people using public transport.

As a first step, a summit sponsored by the WMO, WHO, UNEP and FAO could begin to design a global strategy for reducing deaths caused by air pollution.

Rajesh Kumar is a project scientist at the National Center for Atmospheric
Research (NCAR), Boulder, Colorado, USA. Vincent-Henri Peuch heads the Copernicus Atmosphere Monitoring Service operated by the European Center for Medium-Range Weather Forecasts in Reading, UK. James H. Crawford is NASA's senior scientist for tropospheric chemistry at the Langley Research Center in Hampton, Virginia, USA. Guy Brasseur is director of the Atmospheric Chemistry Observations and Modeling Laboratory at NCAR. e-mail:rkumar@ucar.edu

1. World Health Organization. Air pollution; available at https://go.nature.com/2bzdas7

2. Kumar, R. et al. J. Geophys. Res. Atmos. 123, 1840-1864 (2018)

3. Avnery, S., Mauzerall, D. L., Liu, J. \& Horowitz, L. W. Atmos. Environ. 45, 2284-2296, (2011).

4. Ghude, S. D. et al. Geophys. Res. Lett. 41, 5685-5691 (2014).

5. World Bank \& Institute for Health Metrics and Evaluation. The Cost of Air Pollution:

Strengthening the Economic Case for Action (International Bank for Reconstruction and Development/World Bank, 2016); available at https://go.nature.com/2mluupw

6. Russell, A. G. et al. Impacts of Regulations on Air Quality and Emergency Department Visits in the Atlanta Metropolitan Area, 1999-2013 HEI Research Report 195 (Health Effects Institute, 2018).

7. Parrish, D. D., Xu, J., Croes, B. \& Shao, M. Front. Environ. Sci. Eng. 10, 11 (2016).

8. Chen, H. et al. Lancet Planet. Health 2, e19-e26 (2018).

9. Mullins, J. \& Bharadwaj, P. Am. J. Agric. Econ. 97, 1107-1134 (2015).

10.Chandra, B. P. et al. Curr. Sci. 114, 1318-1325 (2018).

11. Hov, Ø. et al. Nature 552, 168-170 (2017).

12. Kulmala, M. Nature 553, 21-23 (2018). 